\title{
PENYULUHAN TENTANG BAHAYA MEROKOK PADA SISWA-SISWI SMKN 2 PANGANDARAN
}

\author{
Umar Sumarna, Udin Rosidin dan Dadang Purnama \\ Departemen Keperawatan Komunitas, Fakultas Keperawatan, Universitas Pandjadjaran \\ E-mail: umar.sumarna@unpad.ac.id
}

\begin{abstract}
ABSTRAK. Indonesia merupakan negara dengan jumlah perokok terbanyak di ASEAN, Sementara itu, jumlah perokok Indonesia dengan umur lebih dari 10 tahun paling tinggi terdapat di Provinsi Jawa Barat. Kabupaten Pangandaran adalah salah satu kabupaten di Jawa Barat yang dijadikan tempat wisata. Sebagai tempat wisata, kabupaten ini berpotensi memiliki jumlah perokok banyak, karena lingkungan sosialnya mendukung remaja putra-putrinya untuk memiliki perilaku kebiasaaan merokok. Seperti pada sekolah-sekolah menengah atas lainnya, maka siswa-siswi SMKN 2 Pangandaran terdiri dari remaja putra-putri yang terkena dampak berupa ancaman bahaya merokok. Dampak tersebut akan semakin mengancam siswasiswi SMKN 2 Pangandaran bila tingkat pengetahuannya tentang bahaya merokok masih rendah, maka tujuan dari PPM ini adalah meningkatkan pengetahuan siswa-siswi SMKN 2 Pangandaran tentang bahaya merokok. Metode yang digunakan adalah metode penyuluhan berupa ceramah yang disertai dengan diskusi. Hasilnya adalah: dari 45 siswa-siswi diperoleh hasil pre test menunjukkan bahwa sebanyak $31,11 \%$ siswa memiliki tingkat pengetahuan baik, $46,67 \%$ sedang, dan $22,22 \%$ kurang, sementara hasil post test sebanyak $71,11 \%$ siswa memiliki tingkat pengetahuan baik, $28,89 \%$ sedang, dan tingkat pengetahuan kurang tidak ada. Maka dapat disimpulkan bahwa: secara kelompok, terjadi peningkatan pengetahuan tentang bahaya merokok dari siswa-siswi SMKN 2 Pangandaran.
\end{abstract}

Kata Kunci: bahaya merokok; tingkat pengetahuan; siswa-siswi

ABSTRACT. Indonesia is the country with the highest number of smokers in ASEAN. Meanwhile, the highest number of Indonesian smokers with more than 10 years of age is found in West Java Province. Pangandaran Regency is one of the districts in West Java that is used as a tourist spot. As a tourist destination, this regency has the potential to have a large number of smokers, because the social environment supports their teenage to have smoking habits. As in other high schools, the students of SMKN 2 Pangandaran consist of the youngs who are affected by the threat of the smoking hazard. The impact will further threaten the SMKN 2 Pangandaran students if the level of knowledge about the smoking hazard is still low. The aimed of The community cervis activity was to increase the knowledge of the SMKN 2 Pangandaran students about the smoking hazard. The method used is a counseling method in the form of lectures accompanied by discussions. The result was: from 45 students obtained pre-test results showed that as many as $31.11 \%$ of the students had a good level of knowledge, $46.67 \%$ was fair, and $22.22 \%$ was poor, while the results of post-test was $71.11 \%$ the students had a good level knowledge, 28.89\% was fair, and there wasn't the poor level of knowledge. Then it could be concluded that: as a group, there was an increase in level of knowledge about the smoking hazards of the SMKN 2 Pangandaran students.

Keywords: the smoking hazard; level of knowledge; students

\section{PENDAHULUAN}

Kondisi masyarakat Indonesia saat ini terancam secara serius oleh dampak negatif dari produk-produk rokok yang sangat merugikan bagi kesehatan, terutama dapat menimbulkan penyakit paru-paru dan Jantung. Setidaknya 50\% perokok aktif di dunia meninggal karena penyakit yang di sebabkan oleh kebiasaaan merokok (Rahayu, 2017).

ASEAN Region menunjuk Indonesia merupakan negara dengan jumlah perokok terbanyak di Asean, yaitu 65,19 juta orang. Angka tersebut setara dengan 34\% dari total penduduk Indonesia pada 2016.

(Laporan SEATCA 2016). Sementara itu pada tahun 2018 di Indonesia sendiri jumlah perokok dengan urutan tertinggi jatuh pada Provinsi Jawa Barat dengan jumlah sebesar 32,2\%. Angka tersebutat jauh di atas angka nasional sebesar 28,8\% (Riskesdas Kemenkes RI 2018 Salah satu kabupaten di propinsi Jawa Barat yaitu Kabupaten Pangandaran.
Kabupaten ini terletak di ujung timur Provinsi Jawa Barat dan berbatasan lansung dengan Provinsi Jawa Tengah. Sementara di bagian selatan berbatasan langsung dengan Samudra Indonesia.

Karena kondisi geografisnya yang sangat strategis, maka kabupaten ini menjadi salah satu tempat yang menjadi tujuan wisata bagi para pelancong baik dari dalam maupun luar negeri. Pada tahun 2018 tercatat jumlah pengunjung wisata Pangandaran sebanyak 4.177.876 orang (Disparbud Kab. Pangandaran, 2018). Secara tidak langsung kondisi ini membuat pergaulan remaja putra putri sangat berbaur secara padat dan bervariasi. Demikian juga dengan perilaku merokok.

Di tempat seperti ini sangat sulit melarang orang-orang untuk merokok. Kondisi lingkungan sosial seperti ini tentu berpengaruh buruk pada para remaja di Kabupaten Pangandaran. Sementara sekumpulan remajanya berada di setiap sekolah menengah tingkat atas yang ada di seluruh pelosok di Kabupaten Pangandaran. 
Sementara itu, situasi yang lebih memperberat remaja sekolah di Kabupaten Pangandaran adalah kesibukan orang tuanya mayoritas nelayan dan berdagang (Pemerintah Kab. Pangandaran, 2018). Kondisi ini membuat mereka tidak banyak waktu untuk mengawasi dan membimbing anakanaknya.

Pendidikan sekolah menengah tingkat atas di Kabupaten Pangandaran Terdiri dari Sekolah Menengah Atas (SMA) dan Sekolah Menengah Kejuruan (SMK). Saat ini jumlah sekolah SMA di Kabupaten Pangandaran ada 4 buah milik negeri, 2 buah milik swasta, sedangkan untuk SMK, ada 5 buah milik negeri, 27 buah swasta (Pemerintah Kab. Pangandaran, 2018).

Salah satu sekolah di Kabupaten Pangandaran yang menjadi sasaran penulis adalah SMKN 2 Pangandaran dengan alasan karena jumlah siswa-siswinya cukup banyak, yaitu sebanyak 263 yang tediri dari siswa berjumlah 145 orang dan siswi 118 orang. Sekolah ini beralamat di Jalan Cintaratu Desa Cintaratu Kecamatan Parigi Kabupaten Pangandaran.

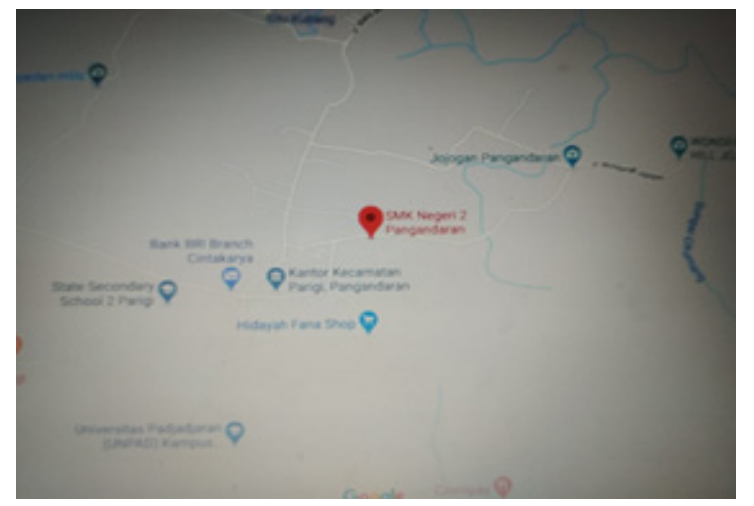

Gambar 1. Peta Lokasi PPM

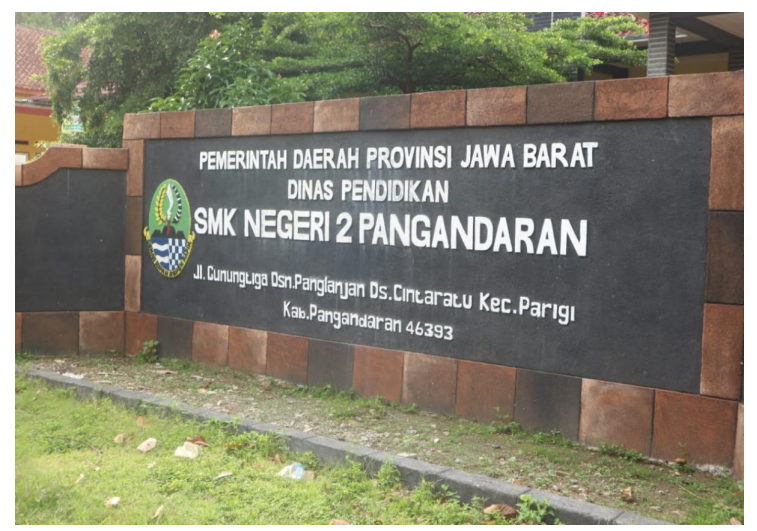

Gambar 2. Lokasi Kegiatan PPM

Untuk merubah kondisi lingkungan sosial di Kabupaten Pangandaran sudah jelas sangat sulit, maka salah satu yang bisa diupayakan adalah meningkatkan pengetahuan tentang bahaya merokok (Meliana, 2017). Maka dengan pengetahuan yang meningkat, dengan sendirinya kesadaran siswa-siswi tentang bahaya merokok bagi kesehatan akan meningkat pula.
Berdasarkan hal tersebut di atas, maka tujuan dari kegiatan PPM ini adalah meningkatkan pengetahuan siswa-siswi SMKN 2 Pangandaran tentang bahaya merokok, dengan harapan akan berdampak pula pada perilakunya untuk tidak merokok dalam kehidupan sehari-harinya.

\section{METODE}

Kegiatan PPM dilaksanakan melalui metode penyuluhan yaitu dengan melakukan ceramah interaktif pada peserta didik siswa-siswi SMKN 2 Pangandaran melalui 5 tahap, yaitu:1. Melakukan pretest, 2. Memberikan materi tentang bahaya merokok, 3. Diskusi dan tanya jawab, 4. Evaluasi melalui post test. 5 Pemberian door prize bagi 3 orang siswa-siswi yang mendapat nilai tertinggi, yaitu peringkat satu, peringkat dua, dan peringkat tiga. Pada penyelenggaraannya, kegiatan ini dibantu oleh mahasiswa angkatan 16 Fkep Unpad PSDKU Pangandaran berkaitan dengan penyusunan acara dan pengadaan logistik yang harus dipersiapkan.

\section{Teknik Pengumpulan Data}

Dari populasi sebanyak 263 siswa-siswi SMKN 2 Pangandaran, diambil data dengan teknik pengambilan sampel secara cluster sampling, yaitu hanya kepada siswa-siswi kelas 12 SMKN 2 Pangandaran sebagai siswa-siswi yang paling senior di sekolah ini. Data yang diambil adalah data tentang tingkat pengetahuan siswa-siswi melalui pre-test dan post test berupa lembar pertanyaan yang diberikan pada masing-masing. Isi dari soal pre test dan post test dibuat sama yang berisi 20 pertanyaan berupa soal pilihan berganda. Lembar jawaban dikumpulkan, kemudian masing-masing diberi nilai dengan rentang nilai $0-100$. Nilai dari siswa siswi tersebut dikelompokkan menjadi 3 kategori, yaitu kategori nilai baik 76-100, nilai sedang 56-75, nilai kurang $<56$ (Arikunto, 2016).

\section{Teknik Analisis Data}

Setelah nilai dari masing-masing dikelompokkan kepada masing-masing kategori, maka hasilnya dimasukkan ke dalam sebuah tabel distribusi frekuensi untuk mendapatkan nilai frekuensi dan persentase dengan rumus dari Sugiyono (2016), yaitu: $\mathrm{P}=\mathrm{F} / \mathrm{N} \times 100 \%$, dimana $\mathrm{P}=$ Persentase, $\mathrm{F}=$ frekuensi, dan $\mathrm{N}=$ Jumlah yang diobservasi atau sampel.

\section{HASIL DAN PEMBAHASAN}

Hasil dan pembahasan dari tiap-tiap tahap penyuluhan dapat dijelaskan secara rinci sebagai berikut: 


\section{Melakukan Apersepsi dengan Pre test}

Pre test dilaksanakan untuk mengetahui sejauhmana tingkat pengetahuan siswa-siswi tentang bahaya merokok. Pengetahuan tersebut bisa didapat dari guru-gurunya, orang tuanya, tetangganya ataupun dari teman-teman sekolahnya, maupun teman-teman sepermainannya.

Soal pre test pengetahuan yang diberikan sebanyak 20 soal pilihan ganda dengan 4 alternatif jawaban yang pertanyaannya berkaitan dengan materi-materi yang akan diberikan.

Adapun hasil yang diperoleh siswa-siswi SMKN 2 Pangandaran dalam pre test dapat dilihat pada tabel di bawah ini :

Tabel 1. Hasil Pre test Siswa-siswi SMKN 2 Pangandaran

\begin{tabular}{clccc}
\hline No & $\begin{array}{c}\text { Tingkat } \\
\text { Pengetahuan }\end{array}$ & $\begin{array}{c}\text { Frek } \\
(\mathrm{F})\end{array}$ & $\begin{array}{c}\text { Present } \\
(\mathrm{P} / \%)\end{array}$ \\
\hline 1 & Baik & 14 & 31,11 \\
2 & Sedang & 21 & 46,67 \\
3 & Kurang & 10 & 22,22 \\
\hline \multicolumn{2}{r}{ Jumlah } & 45 & 100 \\
\hline
\end{tabular}

Tabel di atas menunjukkan bahwa 31,11\% siswa mendapat nilai baik, 46,67\% siswa mendapat nilai kurang. dan $22,22 \%$ siswa mendapat nilai kurang.

Dari hasil pre test menunjukkan gambaran bahwa pada dasarnya siswa-siswi SMKN 2 Pangandaran sudah sedikit mengenal tentang bahaya merokok, terbukti hanya $22,22 \%$ yang mendapat nilai kurang.

\section{Memberikan materi tentang bahaya merokok}

Dalam memberikan materi tentang bahaya merokok pada siswa-siswi SMKN 2 Pangandaran materi yang disampaikan terdiri dari: 1. Pengertian Rokok, 2.Alasan Orang Merokok, 3. Pengertian Perokok Aktif dan Perokok Pasif, 4. Bahan-Bahan Rokok yang Berbahaya Bagi Kesehatan, 5. Penyakit yang Ditimbulkan oleh Rokok.

Inti dari materi yang diberikan adalah menjelaskan kandungan bahan kimia yang berbahaya pada tembakau atau rokok yang dihisap setiap harinya oleh para perokok seperti yang diungkapkan oleh Masyitah (2017) kandungan bahan kimia berbahaya yang terkandung pada tembakau adalah Karbonmonoksida, Nikotin, Amonia, Phenol, Hidrogensulfida, Asam format dan lain-lain.

\section{Diskusi dan tanya jawab}

Setelah seluruh materi selesai diberikan, siswa-siswi diberi kesempatan untuk bertanya tentang materi yang dirasa masih kurang jelas. Pada kesempatan ini ada 3 siswa yang meminta penjelasan ulang dari sebagian materi yang baru saja diberikan.

Selain itu siswa-siswi bertanya dan meminta solusi bagaimana cara mengatasi untuk menghindari kebiasaan merokok. Dalam hal ini kami tidak langsung dijawab secara doktrinasi, tapi dilemparkan dulu kepada teman-temannya, sehingga suasana diskusi jadi benar-benar hidup.

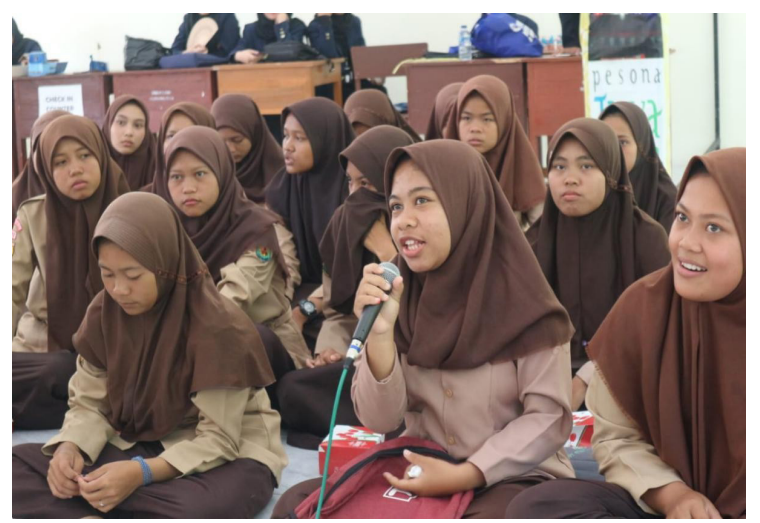

Gambar 3. Siswa-siswi SMKN 2 sedang melaksanakan kegiatan diskusi dan tanya jawab.

\section{Evaluasi melalui Post test}

Setelah acara diskusi dan tanya jawab selesai, maka untuk mengetahui pemahaman siswa terhadap materi yang diberikan sebagai tolak ukur dari perkembangan tingkat pengetahuan siswa setelah diberi materi tentang bahaya merokok, maka dilakukan evaluasi dengan cara memberikan post test yang kontennya sama sengan soal pre test. Adapun hasilnya dapat dilihat pada tabel di bawah ini:

Tabel 2. Hasil Post test Siswa-siswi SMKN 2 Pangandaran

\begin{tabular}{llcc}
\hline No & \multicolumn{1}{c}{$\begin{array}{c}\text { Tingkat } \\
\text { Pengetahuan }\end{array}$} & $\begin{array}{c}\text { Frek } \\
(\mathrm{F})\end{array}$ & $\begin{array}{c}\text { Present } \\
(\mathrm{P} / \%)\end{array}$ \\
\hline 1 & Baik & 32 & 71,11 \\
2 & Sedang & 13 & 28,89 \\
3 & Kurang & 0 & 0 \\
\hline & Jumlah & 45 & 100 \\
\hline
\end{tabular}

Tabel di atas menunjukkan bahwa $71,11 \%$ siswa mendapat nilai baik, $28,89 \%$ siswa mendapat nilai kurang. dan tidak ada yang mendapat nilai kurang.

Hasil post test diatas menunjukkan bahwa setelah diberikan materi tentang bahaya merokok, ternyata terdapat peningkatan, dimana yang mendapat nilai baik menjadi $71,11 \%$, yang mendapat nilai sedang menjadi $28,89 \%$, sementara yang mendapat nilai kurang tidak ada.

Agar lebih jelas lagi, peningkatan dari tingkat pengetahuan siswa-siswi SMKN 2 Pangandaran dapat digambarkan pada gambar 5 .

Melihat kondisi demikian, kita sebagai petugas kesehatan sebenarnya tidak sulit untuk memberikan pengetahuan tentang bahaya merokok pada remaja sekolah. Hal ini disebabkan bahwa hampir di setiap sekolah diadakan program Usaha Kesehatan Sekolah (UKS). Dalam kegiatan UKS, seringkali ada guru 
yang memberikan materi tentang bahaya merokok. Jadi yang menjadi masalah pokok dari remaja sekolah bukanlah masalah pengetahuannya, namun situasi lingkungan yang tidak terkontrol oleh guru dan orang tua siswa. Menurut Notoatmodjo (2016), Perilaku Merokok sangat merugikan kesehatan.

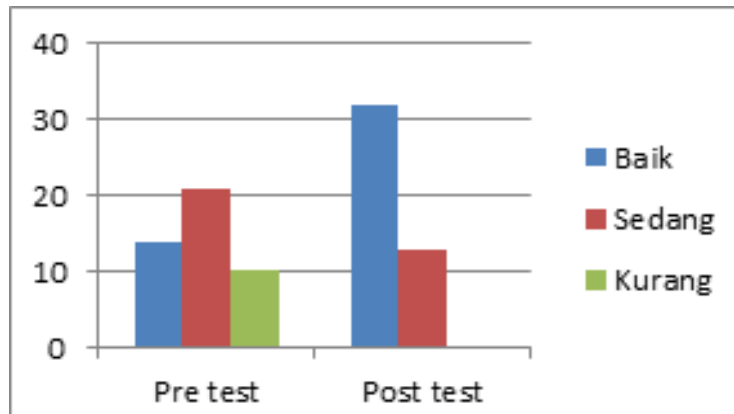

Gambar 5. Grafik Peningkatan Tingkat Pengetahuan dari Pre test ke Post test tentang Bahaya Merokok dari Siswa-siswi SMKN 2 Pangandaran

Untuk itu sebaiknya siswa dialihkan supaya diperbanyak aktivitas di sekolahnya, supaya tidak banyak kesempatan untuk mengadakan kegiatan yang memberikan pengaruh buruk di luar sekolah, seperti membentuk genk, mabuk-mabukan, ataupun hanya sekedar kumpul-kumpul dengan begadang setiap malam dan melakukan kegiatan-kegiatan yang kurang bermanfaat. Dalam hal ini diperlukan pengawasan orang tua yang lebih ketat lagi. Jadi kolaborasi dari didikan guru dan orang tua akan lebih efektif.

\section{Pemberian doorprize pada siswa-siswi dengan nilai tertinggi}

Pencapaian nilai pre test dan post test dari siswa-siswi dikombinasikan dengan cara : $25 \%$ pre test $+75 \%$ post test. Hasilnya diambil untuk menentukan nilai akhir, untuk memililih 3 siswasiswi yang mendapat nilai tertinggi.

Pada kesempatan ini ada 3 siswa-siswi yang dinyatakan mendapat nilai tertinggi sebagai peringkat 1, 2, dan 3. Mereka disuruh maju kedepan dan mendapat door prize yang sumber dananya dari hasil iuran dari kami dan mahasiswa FKep Unpad PSDKU Pangandaran.

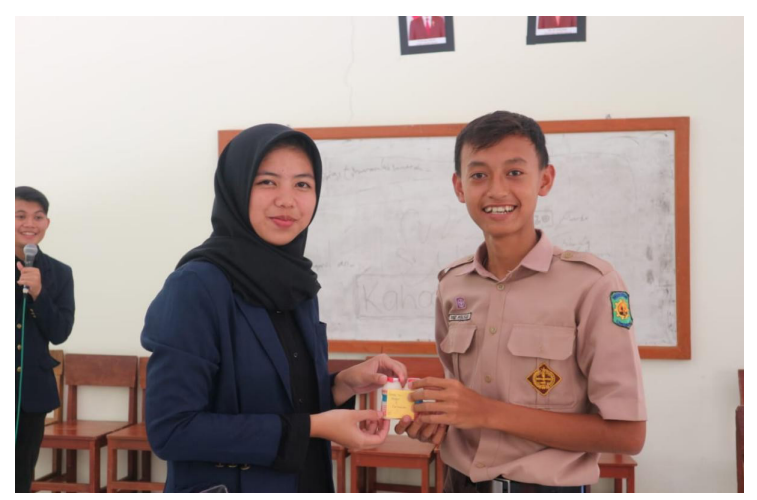

Gambar 4. Pemberian Door Prize pada siswa dengan nilai tertinggi

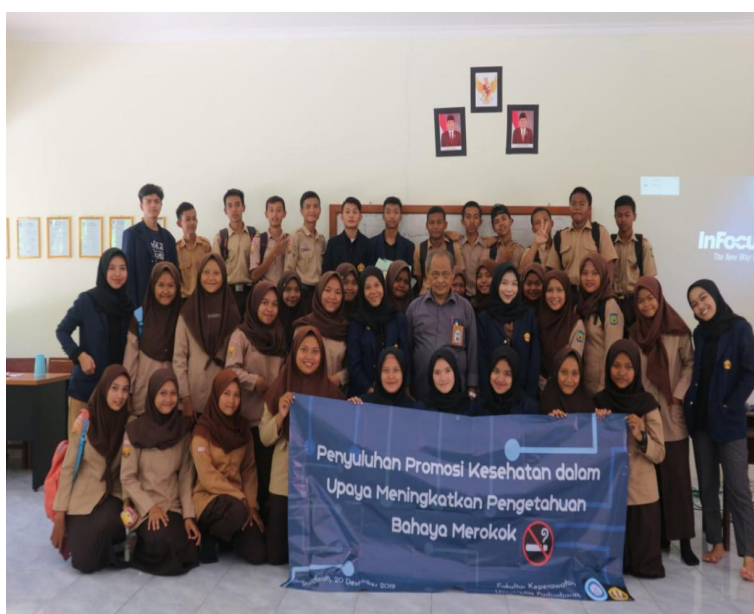

Gambar 6. Photo bersama setelah kegiatan PPM selesai

\section{SIMPULAN}

Pada dasarnya siswa-siswi SMKN 2 Pangandaran sudah mengetahui bahaya merokok. Sebetulnya hal ini merupakan modal awal yang baik dalam mengarahkan perilaku siswa-siswi agar tidak membiasakan diri untuk merokok. Namun rupanya kondisi ini tidak cukup untuk membentuk perilaku siswa soal kebiasaan merokok. Maka salah satu solusinya adalah mengontrol siswa-siswi agar tidak terjebak pada lingkungan yang dapat merusak kesehatan bahkan akhlak siswa-siswi SMKN 2 Pangandaran.

\section{UCAPAN TERIMAKASIH}

Pada kesempatan ini, saya sampaikan ucapan terima kasih kepada:

1. Kepala Sekolah SMKN 2 Pangandaran, guruguru serta staf yang lainnya atas kerjasamanya sehingga PPM ini dapat terlaksana dengan lancar.

2. Mahasiswa Angkata 2016 Fakultas Keperawatan Unpad PSDKU Pangandaran yang telah membantu dalam mempersiapkan terselengaranya kegiatan PPM.

\section{DAFTAR PUSTAKA}

Arikunto, S.(2016). Prosedur Penelitian: Suatu Pendekatan Praktik. Yogyakarta: Rineka Cipta.

Disparbud Kab. Pangandaran. (2018). Laporan Perbandingan Tingkat Kunjungan Wisatawan Tahunan Kabupaten Pangandaran. Pangandaran: Dinas Pariwisata dan Kebudayaan Kabupaten Pangandaran. $3 \mathrm{hlm}$

Masyitah, S. (2017) Analisis Determinan Perilaku Merokok Pada Remaja di Asia Tenggara Menggunakan Pendekatan Meta-Analisis. (Tesis). Padang: Universitas Andalas. 
Meliana, Erwin Tri. (2017). Pengaruh Pendidikan Kesehatan Tentang Bahaya Merokok Terhadap Minat Berhenti Merokok Pada Siswa SMPN2 Tempel. (Skrpsi). Yogyakarta: PSIK Fakultas Ilmu Kesehatan. Universitas 'Asyisyiah Yogyakarta.

Nototmodjo, Sukidjo (2018). Ilmu Perilaku Kesehatan. Yogyakarta: Rineka Cipta.

Pemerintah Kabupaten Pangandaran.(2018). Profil Kabupaten Pangandaran 2018. Pangandaran: pemerintah Kabupaten Pangandaran

SEATCA. (2016). The tobacco control atlas: ASEAN region. 3rd ed. Bangkok: Southeast Asia Tobacco Control Alliance.
Sugiyono. (2016). Metode Penelitian, Kuantitatif, Kualitatif, dan R\&D. Bandung: Penerbit Alfabeta

Rahayu, Purni. (2017). Hubungan Antara Pengetahuan Bahaya Merokok dengan Perilaku Merokok pada Mahasiswa di Universitas Muhammadiyah Surakarta. (Skripsi). Surakarta: Universitas Muhammadiyah Surakarta.

Riskesdas Kemenkes RI (2018). Hasil Utama Riskesdas 2018. Jakarta: Badan Penelitan dan Pengembangan Kesehatan Kemenkes RI. 